\title{
Brand Loyalty versus Brand Switching: Revisiting the Concept from Young Consumers' Perspective
}

\section{Aasir Ali*, Arshad Khushi Muhammad**, Muhammad Shahid Rasheed ${ }^{* * *}$ and Rab Nawaz Lodhi ${ }^{* * * *}$}

\begin{abstract}
Over the years, the usage of smartphones has burgeoned worldwide. However, it is noteworthy that with this multiplied usage and popularity of smartphones, most of the consumers demonstrate erratic behavior in the selection of their preferred brand. Therefore, in order to understand this phenomenon further, this study was conducted in Pakistan to examine the brand switching behavior of young consumers in the smartphone industry. For the purpose of this study, a theoretical framework marks out the relationships between social influence, sales promotion, variety seeking and brand switching. The methodology adopted for this study comprised of a quantitative research design, following a positivistic research paradigm. A sample of 500 young smartphone users from the population of major cities of Pakistan was approached using purposive-sampling method, from which 482 responses were acknowledged. The data was collected via the survey method, following close ended questionnaires. The data was then analyzed by applying the structural equation modeling technique. The research findings filled in the research gaps by revealing a positive relationship between social influences, variety seeking and sales promotion on brand switching. However, brand loyalty was found to have a significant unfavorable impact on these relationships. Brand loyalty weakens the relationship of social influence, variety seeking and sales promotion with brand switching. Hence, the presence of brand loyalty restricts consumers from switching their smartphone brand due to the influence of the above mentioned factors.
\end{abstract}

Keywords: Brand loyalty, brand switching, young consumers, smartphone JEL Classification: M30, M31, N3, O33, L60.

\footnotetext{
${ }^{*}$ Lecturer, Noon Business School, University of Sargodha, Sargodha, Pakistan.

${ }^{* *}$ Research Scholar, University of Engineering \& Technology, Lahore, Pakistan.

${ }^{* * *}$ Lecturer, Noon Business School, University of Sargodha, Sargodha, Pakistan.

${ }^{* * * *}$ Associate Professor, University of Central Punjab, Lahore, Pakistan.
} 


\section{Introduction}

The development and advancement of smartphones has increased with the passage of time. This is mainly due to the changes in the elements which pertain to the buyers' needs and inclinations (Ahad \& Anshari, 2017). Among these advances, smartphones have been one of the best household devices amongst any technological innovation in the current times (Das \& Khan, 2016). Moreover, smartphones are also turning into a crucial part of individual correspondence and communication across the globe. In today's smartphone market, product managers are constantly struggling to locate the most innovative and latest competitive edge, and strive to differentiate themselves for buyers so as to choose their preferred brand, instead of that of the other competitors (Narayan, Rao, \& Saunders, 2011).

In this regard, studies by both, Lambert and Laurent (2010), and, Sasmita and Suki (2015) argue that mostly young customers are found to be involved in brand switching, while more experienced purchasers do the opposite. Gronhoj (2007) and Norazah (2013) both explained that once adolescents reach the age of 16 , they are perceived as youngsters, till they hit the age bracket of 30 . After that they are considered completely grown up, that is, in other words, mature adults. It is at this point that they have entered in the segment of middle-aged individuals. In the same manner, young individuals are very much influenced with the advanced technology due to its numerous advantages. Hence, they are usually emotional in choosing, and utilizing technological products and services like smartphones and social media networks (Ali \& Lodhi, 2017; Jin, Yoon, \& Ji, 2013). From another perspective, some authors (Ali, 2017; Ameen \& Gorman, 2009) revealed, in different time spans, that generally, in the world, and particularly in Pakistan, all the communities are constantly learning about their surroundings and are more aware than they have ever been. Consequently, the youth is well aware of various brands, their functions, differences and the properties that they have to offer in their smartphones.

To conclude the analysis, Batra, Ahuvia, and Bagozzi (2012) portrayed in their study that the buyer's behavior is mostly dependent on some influencing factors i.e. brand loyalty, variety and promotion etc. These factors determine the direction of behavior in terms of the decision 
to either to stay or to shift from the brand. Hebblethwaite, Parsons, and Spence (2017) reported that a particular phenomenon can be widely seen, usually in the Smartphone industry, where many factors compel consumers to shift to other brands.

The profit share of existing smartphone providers is decreasing day by day, and new competitors are succeeding because young, smartphone users do not show loyalty to a particular brand (Msaed, Al-Kwifi, \& Ahmed, 2017). Due to the unpredictable changes in the preference of consumers, revenue and demand of particular Smartphone brands is not able to reach and predict stability. The factors responsible for this erratic and unpredictable behavior need to be analyzed deeply (Baxendale, Macdonald, \& Wilson, 2015; Miller, Chandler, \& Mouttapa, 2015; Taute \& Sierra, 2014). Therefore, the concept of brand loyalty needs to be revisited from another perspective in this industry (Hebblethwaite et al., 2017; Yeh, Wang, \& Yieh, 2016).

In this regard, the following two research questions have been put forth that this study intends to answer.

1) What is the relationship between social influence, sales promotion and variety seeking and brand switching in the smartphone industry?

2) Does brand loyalty moderate the relationship between social influence, sales promotion and variety seeking, and brand switching in the smartphone industry?

Research shows that only a few studies are conducted with a particular focus on brand switching, when it comes to the usage of smartphones amongst the youth (Sasmita \& Suki, 2015; Kumar \& Menon, 2017). Similarly, Msaed et al. (2017), along with Al-Kwifi and Ahmed (2015), reported in their findings that research studies based on the brand switching of smartphones are not adequate enough, especially in the context of South Asia, particularly in India and Pakistan. Moreover, studies conducted in other Asian countries are not sufficient to cover this gap either, as the context, culture and commercial framework of the Subcontinent (India and Pakistan) is entirely different from its neighboring countries i.e. China, Iran and Afghanistan. Similarly, investigation by AlKwifi (2016) elaborates that various studies are done in the past, in order 
to unearth the latest trends in the telecommunication sector of the subcontinent. But smartphones are ignored throughout this era, particularly in terms of the brand switching of high technology products, i.e., smartphones for instance.

\section{Literature Review and Hypotheses}

Chadha and Kapoor (2009) have defined brand loyalty as one of the major dimensions of brand equity, which is the overall worth of the brand. Consumers tend to be loyal, as the customer satisfaction is considered to be the finest predictor of brand loyalty.

Sharma, Kapse, and Sonwalkar (2016) elaborated on brand loyalty as a powerful resistance to switching behavior. Therefore, a vast majority of the organizations consider it as a source of upper hand. It builds income, boosts goodwill, minimizes customer acquisition expenses and brings down the expenses of serving repeat buyers (Nguyen, Barrett, \& Miller, 2011; Villanti et al., 2012).

On the contrary, brand switching is a state in which an individual shifts from purchasing one brand of a product, to buying a different brand, and is usually not satisfied with a single brand. Consumers usually shift between various brands as they seek to reach a desired level of satisfaction (Solomon, 2006). As far as brand switching in youngsters is concerned, findings of Sahay and Sharma (2010) point towards the fact that youngsters usually do not develop strong relationships with any particular brand. Furthermore, Sasmita and Suki (2015) argued that young customers switch brands frequently, while more experienced purchasers tend to show consistency in this regard.

\subsection{Social Influence}

Social groups usually illuminate and make individuals aware of particular products and brands. They encourage people to go into certain states of mind, and influence people to acknowledge dispositions and behaviors that are reliable with the standards of the society (Narayan et al., 2011).

McAlexander, Schouten, and Koenig (2002) found in their study that most of the consumers are dependent on other relatives or social circle 
peers in order to aid them in selecting which brand to acquire, and which to switch. They appreciate the opinions of their loved ones, and mostly help their social group individuals in selecting high priced products or services i.e. property, smartphones, travelling related products, apparels, cosmetics and others.

Probing further into the literature, the investigations of Suki (2013) and Prasad \& Kumar (2016) in India have revealed that social group suggestions have been reported as a critical constraint in the shopping malls while making purchase decisions. These suggestions tend to affect mentalities, inclinations, reasons to buy a product and basic leadership. The studies concluded that it is important for the smartphone brands to understand, and value these social influences, because a strong social influence resists customers from sustaining the loyalty towards the same brand, and assist in choosing the new brand.

Harris, Gordon, MacKintosh, and Hastings (2015) explained that one's social circle can influence individuals to switch from an existing brand to another brand that they are consuming. Social individuals can affect consumers in such a manner that peers and colleagues can motivate and encourage consumers to adopt another brand by justifying its outperforming features and functions. In the same way, Khalek (2014) discovered that there exists a strong positive relationship between social influence and brand switching. As per this discussion, the following hypothesis was proposed to examine the link between social influences and brand switching.

Hypothesis 1: Social influences positively relate to brand switching.

\subsection{Sales Promotion}

Sales promotion is a type of promotion in marketing. Sales promotions comprise of different incentives mainly price concessions, premiums and coupons, which are mostly applicable in the short term. It is a good idea to boost short term sales for a certain time period. In this regard, the purpose of sales promotion is to shift products, albeit inexpensively consumers from an existing brand to a new brand, which is offering the same level of (Heerde, Gupta, \& Wittink, 2003; Kotler, 2015). 
Additionally, Buil, Chernatony, and Martínez (2013) explained the different ways in which sales promotional campaigns for smartphones are usually conducted. These campaigns usually include price concessions, premiums, rebates, discount coupons, trade shows, contests and lucky draws that are organized by smartphone brand owners in order to shift consumers from other brands to their respective brands. Similarly, exchange offers in which an old device is exchanged with a fraction of a cost, and free shipping are also effective tools for promoting sales of electronic devices.

To wind up the argument, Nagar (2009) discussed in his study that sales promotion has a strong relationship with brand switching as both factors can enhance each other. On the premise of the above contentions, one might conclude;

Hypothesis 2: Sales promotion is positively related to brand switching.

\subsection{Variety Seeking}

Ratner and Kahn (2002) recognized the act of variety seeking as a phenomenon of 'need for uniqueness'. It is identified by choices that have not been picked by others. Purchasers who have the need to achieve a high level of uniqueness are more attracted and prone to switching items as compared to low-uniqueness customers. Consequently, these customers are more challenging to convince to display brand loyalty. Basically, variety seeking customers "seek change for the sake of change."

Similarly, Esch, Langner, Schmitt, and Geus (2006) portrayed in their study that there is a specific relationship between switching behavior and variety seeking for a product or service. It can be defined as an internal wish or aspiration to get a new brand, which can be due to many reasons i.e. services, aesthetics, features or even the inner desire for a new brand. Sometimes, innovation can compel consumers to resort to variety seeking behavior against the current brand that they are utilizing.

An investigation directed by Jensen and Hansen (2006) unearths that variety-seeking customers do not stay loyal. Such consumers are always looking for an opportunity to try different brands. Unintentionally, such behavior affects the loyalty ranking of customers, and puts brand managers 
in a complicated situation of offering and managing loyalty programs. As a result, the effect of variety seeking and customer satisfaction on loyalty constantly needs to be reestablished. Variety seeking, especially its true form, may be an important factor that could assist in explaining and predicting brand switching in customers. However, it is not the only factor that could assist in this regard (Kotler, 2015).

Lastly, Sloot and Verhoef (2008) suggested a constructive relationship between brand switching and variety seeking in a manner that both factors boost each other. They explored that variety seeking can explain brand switching widely. Another suggestion directed by Solomon (2006) leads to similar findings. He proposed that brand switching might be easily observed if the overall level of sales promotion is increased for the general consumers. All the above mentioned facts lead to the following hypothesis:

Hypothesis 3: Variety seeking is positively related to brand switching.

\subsection{Moderating Effect of Brand Loyalty}

Sometimes brand loyalty can play the role of a moderating variable, as most of the time it used to reduce or increase the impact of some other latent and manifesting factors in a particular framework (Keller, Apéria, \& Georgson, 2008; Kim, Lee, Bu, \& Lee, 2009). A study conducted by Dooley and Fryxell (1999) reveals that brand loyalty is mostly perceived as a moderating factor in order to increase the influence of independent variables in consumer behavior examinations.

Algesheimer, Dholakia and Herrmann (2005) conducted a study in Europe in order to assess the relationship of brand loyalty and social influence. Interestingly, findings demonstrated that brand loyalty has an inverse relationship with social influence. Similarly, Jensen and Hansen (2006) elaborated that suggestions from one's social circle are often ignored if the consumer possesses a certain level of brand loyalty for a particular product.

A number of researchers explored that sales promotion is a reasonable factor to diminish brand loyalty, and directs the consumers to shift to other brands (Buil et al., 2013; Westberg \& Pope, 2014). Similarly, 
Papatla (2003), as well Algesheimer et al. (2005) observed the inverse impact of brand loyalty on sales promotion. The rationalization of the argument is that internationally well-known brands rarely go for sales promotion.

According to Kotler (2015), the element of brand loyalty resists the consumer from switching to another brand from an existing brand. However, loyalty can be changed with sales promotion by offering various kinds of rebates, coupons, samples, sweepstakes and bonuses. Most of the companies entice the consumers of competitors by weakening their brand loyalty. Brand loyalty deteriorates when companies start offering lucrative promotional deals. A study by Junaedy and Dharmmesta (2002) also confirms the findings of Kotler (2015).

In the same manner, the impact of brand loyalty on variety seeking also exhibits that both variables have a contrary relationship (Belch, Belch, Kerr, \& Powell, 2014). That is to say that variety seeking has the ability to cannibalize brand loyalty. Kotler and Armstrong (2010) argues that in the presence of strong brand affiliation, the need for uniqueness vanishes because consumers are already satisfied, and even sometimes delighted with their current brand choice. Following hypotheses are derived from the above discussion.

Hypothesis 4: Brand loyalty weakens the relationship between social influence and brand switching.

Hypothesis 5: Brand loyalty weakens the relationship between sales promotion and brand switching.

Hypothesis 6: Brand loyalty weakens the relationship between variety seeking and brand switching.

\section{Conceptual Model}

The conceptual model in Figure 1 exhibits that social influence, sales promotion and variety seeking have a positive relationship with brand switching. While brand loyalty has a negative relationship with brand switching, and an inverse impact on the relationship of the aforementioned factors with brand switching. It is imperative to state that the selected variables were found to be the most appropriate for this model, under the explicit context. Most of the previous studies (Kotler \& Keller, 
2016; Solomon, 2006) suggested that these variables i.e. social influence, sales promotion and variety seeking are the most influential variables causing brand switching in youngsters.

\section{Figure 1: Conceptual Model}

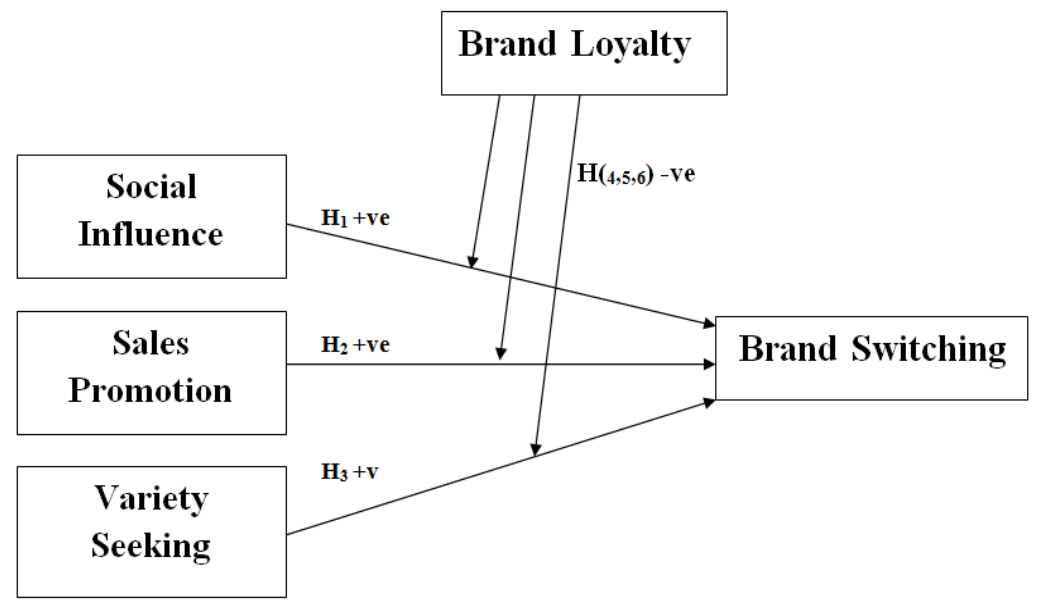

\section{Methodology}

Quantitative research records and computes of customers' behavior, opinions and attitude in the form of numerical information (Gulati, 2009). The intention of this investigation was to conduct a survey; therefore, a quantitative research strategy was adopted following the positivism research paradigm.

This study has been adopted the cross sectional research design. As a result, this examination was constrained to a particular time frame, as one-time information was required (Saunders, Lewis, \& Thornhill, 2012) from young consumers. The data was collected in a non-contrived setting. Furthermore, the youngsters were approached in order to gather data in their natural environment. The research methodology was designed to assess the relationship of various factors with brand switching, while keeping brand loyalty as a moderating variable.

\subsection{Sample and Data Collection}

A purposive sampling technique was adopted in order to carry out this study. Purposive sampling is fundamentally used when choosing a 
specific group of people from the entire populace, as it should be used when one wants to contact a specific subset of the population (Saunders et al., 2012). A total of 500 young university students from all over Pakistan were approached via email, social media and personal means to fill in the designed questionnaires. Out of these 500 questionnaires, a total of 482 responses were acknowledged as shown in Table-1. The assumption and justification for targeting university students was that most of them belong to a socio-economic segment that can afford the smartphone.

Table 1: Demographics of Sample

\begin{tabular}{llcc}
\hline & Values & Frequency & Percentage \\
\hline Gender & Male & 274 & 56.8 \\
Age (years) & Female & 208 & 43.2 \\
& $>18$ & 83 & 17.2 \\
& $18-21$ & 216 & 44.8 \\
& $22-25$ & 152 & 31.5 \\
Education & $26-29$ & 31 & 6.4 \\
& Matric/Below & 17 & 3.5 \\
& Intermediate & 79 & 16.4 \\
Status & Bachelors & 225 & 46.6 \\
& Masters/Above & 161 & 33.4 \\
& Student & 263 & 54.5 \\
& Employed & 89 & 18.4 \\
Monthly Family & Unemployed & 103 & 21.3 \\
Income (Rupees) & Other & 27 & 5.6 \\
& $>25000$ & 68 & 14.1 \\
& $25000-40000$ & 111 & 23 \\
& $41000-55000$ & 161 & 33.4 \\
& $56000-70000$ & 83 & 17.2 \\
& $71000-85000$ & 35 & 7.2 \\
& $85000+$ & 24 & 5 \\
\hline
\end{tabular}

The data was collected through the survey method. A simple 5point Likert scale structured questionnaire was adapted in order to gather information from young smartphone users. The respondents belonged to major cities of Pakistan including Karachi, Lahore, Rawalpindi, Faisalabad, Multan, Bahawalpur, Gujranwala, Sargodha, Dera Ghazi Khan, Hyderabad, Sukkur, Peshawar, Mardan, Dera Ismail Khan, Jafarabad and Quetta. The data was collected over a span of two months approximately. The months of December 2017 and January 2018 were devoted for the data compilation. The age range of the respondents was 16-30 years old, as 
suggested by many authors (Gronhoj, 2007; Sahay \& Sharma, 2010; Sasmita \& Suki, 2015). Most commonly, university students were approached through online and personal sources.

The rationale for targeting university students was straightforward. This study was conducted particularly in the context of the smartphone industry of Pakistan. As a result, only those students were approached who were active smartphone users. It was observed that the data could not be collected from all general consumers. Therefore, a list of those 500 students, who used smartphones, was prepared. Then, these students were requested to fill in the questionnaires. These students were, in most instances, approached personally. Instances where a personal approach was not possible, respondents were contacted through email and social media platforms.

The decision to select the sample size of 500 is also justified in this regard. Comrey and Lee (1992) gave a comprehensive size of the sample measure sufficiency: 50 - poor, 100 - fair, 200 - good, 300 - great, and lastly 500 - excellent. Thus, in order to follow this rule of thumb, a sample size of 500 students was chosen. Furthermore, a total of five constructs were adapted from relevant studies and doctoral dissertations. The questionnaire comprised of two major sections. One for demographic information of the respondents, and the other consisted of the 5 point Likert scale close-ended questions related to the variables of the study. There were a total of 5 variables used in the study. Social influence, sales promotion and variety seeking as independent variables, while brand switching was used as a dependent variable. Brand loyalty was considered to be a moderating variable.

\section{Data Analysis and Findings}

In this research, the Partial Least Square Structural Equation Modeling (PLS-SEM) 3.2 has been applied in order to inspect and deduce the gathered statistics, as recommended by Hair et al. (2017) and Wong (2013). The Smart-PLS software is the most suitable and effective tool for analyzing quantitative data, as Ali (2017), Wong (2013) and many others have used and recommended it. 


\subsection{Measurement Model}

A total of 5 constructs were tested to deduce whether they are valid in terms of the convergent validity and discriminant validity, and if they are reliable in terms of the composite reliability (CR) and Cronbach's alpha. Out of 48 items of constructs, only 31 were kept, and the other 17 were dropped due to having a factor loading value of less than the 0.7 benchmark (Hair et al., 2017). All the kept items of the given five constructs had a factor loading value more than a 0.7 benchmark, and the Average Variance Extracted (AVE) values were more than the threshold of 0.5 (Hair, Hult, Ringle, \& Sarstedt, 2013) as exhibited in Table-2.

Table 2: Convergent Validity

\begin{tabular}{|c|c|c|c|}
\hline Variables & Items & Factor Loadings & AVE \\
\hline \multirow[t]{6}{*}{ Brand Loyalty } & Q1 & 0.773 & 0.587 \\
\hline & Q2 & 0.744 & \\
\hline & Q3 & 0.801 & \\
\hline & Q4 & 0.714 & \\
\hline & Q6 & 0.882 & \\
\hline & Q7 & 0.749 & \\
\hline \multirow[t]{4}{*}{ Brand Switching } & Q9 & 0.848 & 0.558 \\
\hline & Q12 & 0.717 & \\
\hline & Q13 & 0.745 & \\
\hline & Q14 & 0.799 & \\
\hline \multirow[t]{7}{*}{ Sales Promotion } & $\hat{\mathrm{Q}} 15$ & 0.856 & 0.572 \\
\hline & Q16 & 0.740 & \\
\hline & Q18 & 0.835 & \\
\hline & Q19 & 0.752 & \\
\hline & $\hat{\mathrm{Q}} 21$ & 0.724 & \\
\hline & Q23 & 0.743 & \\
\hline & Q26 & 0.774 & \\
\hline \multirow[t]{6}{*}{ Social Influence } & Q27 & 0.762 & 0.844 \\
\hline & Q28 & 0.806 & \\
\hline & Q30 & 0.742 & \\
\hline & Q31 & 0.785 & \\
\hline & Q32 & 0.836 & \\
\hline & Q35 & 0.725 & \\
\hline \multirow[t]{8}{*}{ Variety Seeking } & Q36 & 0.761 & 0.913 \\
\hline & Q38 & 0.707 & \\
\hline & Q39 & 0.762 & \\
\hline & Q40 & 0.720 & \\
\hline & Q41 & 0.817 & \\
\hline & Q43 & 0.837 & \\
\hline & Q44 & 0.795 & \\
\hline & Q46 & 0.855 & \\
\hline
\end{tabular}


All the variables have the average shared value (ASV) of less than their AVE, portraying that all the constructs are distinctive from each other and discriminant validity exists (Hair et al. 2013) as shown in Table 3.

\section{Table 3: Pearson Correlation Coefficients and Discriminant Validity}

\begin{tabular}{lcccccccc}
\hline Variables & Mean & $\begin{array}{c}\text { Standard } \\
\text { Deviation }\end{array}$ & ASV & $\begin{array}{c}\text { Brand } \\
\text { Loyalty }\end{array}$ & $\begin{array}{c}\text { Brand } \\
\text { Switching }\end{array}$ & $\begin{array}{c}\text { Sales } \\
\text { Promotion }\end{array}$ & $\begin{array}{c}\text { Social } \\
\text { Influence }\end{array}$ & $\begin{array}{c}\text { Variety } \\
\text { Seeking }\end{array}$ \\
\hline $\begin{array}{l}\text { Brand } \\
\text { Loyalty }\end{array}$ & 0.387 & 0.019 & 0.097 & $\mathbf{1}$ & & & & \\
$\begin{array}{l}\text { Brand } \\
\text { Switching }\end{array}$ & 0.444 & 0.016 & 0.090 & $0.392^{* *}$ & $\mathbf{1}$ & & & \\
$\begin{array}{l}\text { Sales } \\
\begin{array}{l}\text { Promotion } \\
\text { Social }\end{array}\end{array}$ & 0.305 & 0.016 & 0.064 & $0.284^{*}$ & $0.236^{*}$ & $\mathbf{1}$ & & \\
$\begin{array}{l}\text { Influence } \\
\text { Variety }\end{array}$ & 0.364 & 0.028 & 0.093 & $0.314^{* *}$ & $0.233^{*}$ & $0.281^{* *}$ & $\mathbf{1}$ & \\
Seeking & 0.337 & 0.025 & 0.085 & $0.240^{*}$ & $0.298^{*}$ & $0.225^{*}$ & $0.379^{* *}$ & $\mathbf{1}$ \\
\hline
\end{tabular}

Note: ${ }^{*}$ Values are significant at p-level $<0.05$

** Values are significant at $\mathrm{p}$-level $<0.01$

Table 4 exhibits that all the constructs were accurately reliable, and could be used for further analysis. The values were more than 0.7 of the benchmark value (Tavakol \& Dennick, 2011) for reliability via Cronbach's alpha method and composite reliability.

Table 4: Construct Reliability via Composite Reliability and Cronbach's Alpha

\begin{tabular}{lcc}
\hline Construct & Composite Reliability (CR) & Cronbach's Alpha \\
\hline Brand Loyalty & 0.861 & 0.807 \\
Brand Switching & 0.852 & 0.762 \\
Sales Promotion & 0.844 & 0.758 \\
Social Influence & 0.868 & 0.781 \\
Variety Seeking & 0.913 & 0.822 \\
\hline
\end{tabular}

\subsection{Model Fit Indices}

Table 5 portrays the indicators for model fitness. The df should be between the range of 2 and 5, and all the index indicators must follow a threshold of greater than 0.7. Moreover, the RMSEA is supposed to be less than 0.10 (Henseler et al., 2013; Lohmoller, 2013; Ullman \& Bentler, 2003). All 
the criteria in this regard were met. The model seems to be fit as per the standards suggested by expert researchers mentioned above.

Table 5: Model Fit Indicators

\begin{tabular}{lccccccc}
\hline DF & TLI & AGFI & RFI & NFI & IFI & CFI & RMFSA \\
\hline 3.93 & 7.01 & 7.43 & 7.49 & 7.20 & 7.63 & 7.11 & 0.09 \\
\hline
\end{tabular}

\subsection{Hypotheses Testing and Moderation Analysis}

Moderation testing was executed to determine the relationship of the latent variables, moderation effect and hypotheses testing. Model 1, 2 and 3 (Table 6) were used to test the moderating effect of brand loyalty on the relationships between sales promotion, social influence and variety seeking, and brand switching (dependent variable). Model 1 tested the main effect of these three variables on brand switching. The results were found to be positive and significant. Moderator variable brand loyalty was introduced in Model 2, which tested its direct impact on brand switching. The findings reported a significant negative impact on brand switching.

Table 6: Results of Regression and Moderation Analyses

\begin{tabular}{|c|c|c|c|}
\hline \multirow[t]{2}{*}{ Relationship } & $\begin{array}{c}\text { Main Effect } \\
\text { (Model 1) }\end{array}$ & $\begin{array}{c}\text { Moderator } \\
\text { Direct Effect } \\
\text { (Model } 2)\end{array}$ & $\begin{array}{c}\text { Moderating } \\
\text { Effect } \\
\text { (Model 3) }\end{array}$ \\
\hline & \multicolumn{3}{|c|}{ Latent coefficient (Beta Value) } \\
\hline Sales Promotion $\rightarrow$ Brand Switching & $0.429^{* *}$ & $0.409^{* *}$ & $0.371^{* *}$ \\
\hline Social Influence $\rightarrow$ Brand Switching & $0.424^{* *}$ & $0.380^{* *}$ & $0.404^{* *}$ \\
\hline Variety Seeking $\rightarrow$ Brand Switching & $0.401^{* *}$ & $0.361^{* *}$ & $0.326^{*}$ \\
\hline $\begin{array}{l}\text { Brand Loyalty } \rightarrow \text { Brand Switching } \\
\text { (Moderator } \rightarrow \text { Dependent) }\end{array}$ & -- & $-0.787^{* *}$ & $-0.703^{* *}$ \\
\hline $\begin{array}{l}\text { Brand Loyalty } \times \text { Sales Promotion } \\
\rightarrow \text { Brand Switching }\end{array}$ & -- & -- & $-0.261^{* *}$ \\
\hline $\begin{array}{l}\text { Brand Loyalty } \times \text { Social Influence } \\
\rightarrow \text { Brand Switching }\end{array}$ & -- & -- & $-0.284^{* *}$ \\
\hline $\begin{array}{l}\text { Brand Loyalty } \times \text { Variety Seeking } \\
\rightarrow \text { Brand Switching }\end{array}$ & -- & -- & $-0.228^{*}$ \\
\hline
\end{tabular}

Model 3 includes the three following interaction terms (sales promotion $\times$ brand Loyalty; social influence $\times$ brand loyalty; and variety Seeking $\times$ brand Loyalty). The model provided expected results. For moderating effect between the relationship of sales promotion and brand switching, the coefficient was negative and significant $(b=-0.261, p<0.01)$. 
Similarly, the moderating effect on social influence and brand switching was also negative and significant $(b=-0.284, p<0.01)$. The moderating impact on the relationship of variety seeking, and brand switching was also negative and significant $(b=-0.228, p<0.05)$. Thus, the findings supported all the hypotheses that were proposed. Brand loyalty weakens the impact of all three independent factors on brand switching. $\mathrm{H} 1, \mathrm{H} 2$ and $\mathrm{H} 3$ propose the relationship of independent variables with brand switching. High intensity of variables sales promotion, social influence and variety seeking lead to greater brand switching. The results of the analysis yielded positive and significant standardized coefficients $(b$ sales promotion $=0.429, p<$ $0.01 ; b$ social influence $=0.424, p<0.01 ; b$ variety seeking $=0.401, p<0.01)$ and provide full support to the aforementioned hypotheses. Similarly, H4, H5 and H6 were also supported by findings, reflected that brand loyalty deteriorates the relationship of independent variables with brand switching. These results can be corroborated from the pictorial representation of the SmartPLS model as presented in Figure 2.

Figure 2: SmartPLS Model

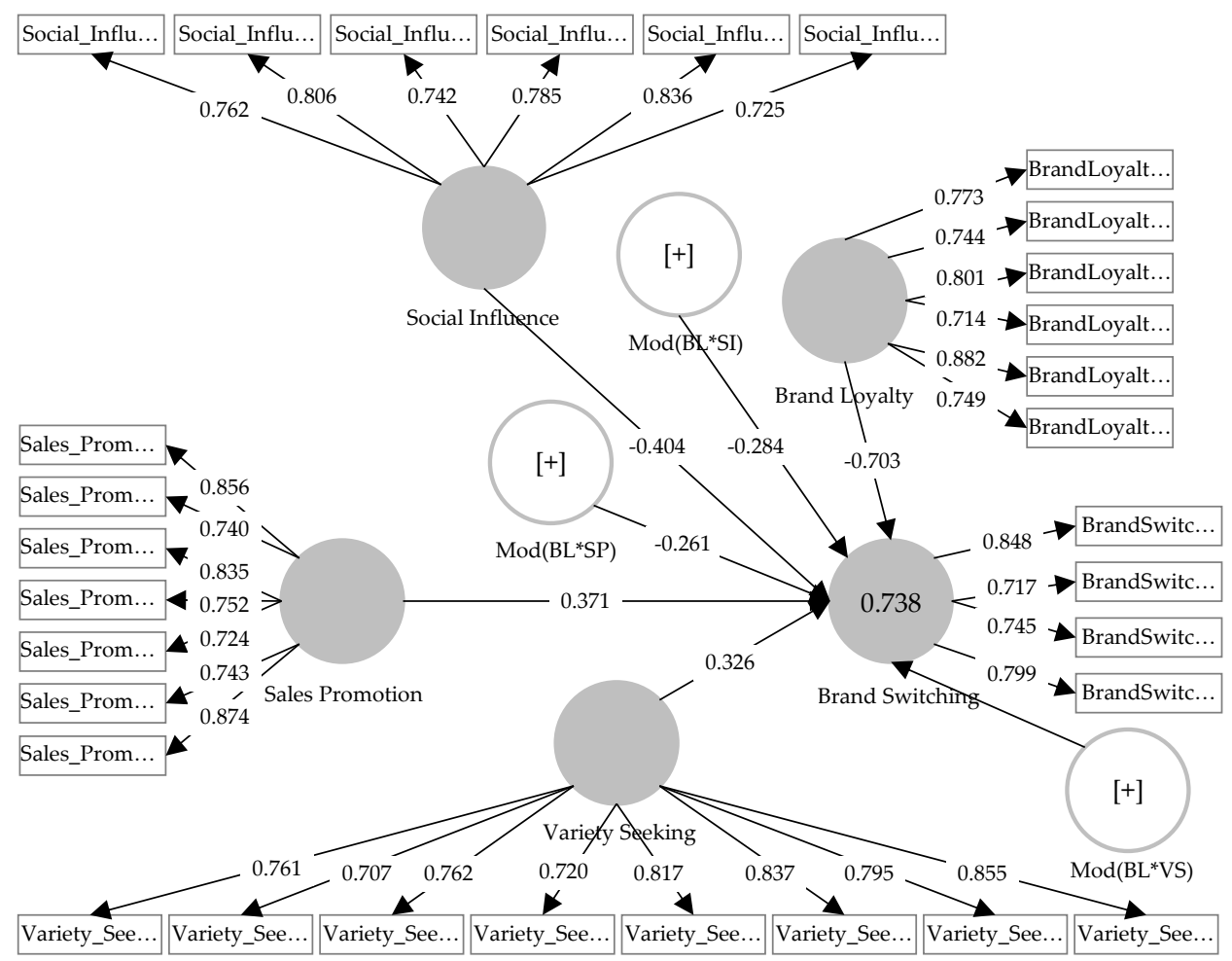




\section{Discussion}

The empirical examination of this study revealed that independent factors (i.e., social influence, sales promotion, and variety seeking) positively linked with brand switching. The relative importance of the top three determinants was close, however, social influence was found to be the most dominant factor. As expected, brand loyalty was found to have an indirect effect on all other variables. The results further exhibited that brand loyalty moderated the effect of all three determinants on brand switching. These findings require discussion. Social influence is the deliberate or unintentional change in behavior, due to the people around (Algesheimer et al., 2005). Once teenagers cross the age of adolescence, their dependency begins shifting from their parents to their social circle (Sahay \& Sharma, 2010). Peer influence can also be observed extensively in Pakistan. The young population are very much attached to their friends, cousins and classmates. In Pakistan, it is a tendency of our society to make decisions collectively. Therefore, the youth practice a certain level of influence on each other's acquisition and consumption related choices. Thus, the impact of brand loyalty developing campaigns is suppressed eventually.

In Pakistan, in most instances, extensive advertising and endorsement is not effective. Merely social approval is enough for a particular brand to have a desirable demand. Another dominant factor in this regard is social media. In order to conform to the choice of consumers, a brand has to be viral on social media. Interestingly, social media is considered to be the most influential medium of all times. In a very limited duration, it has replaced the other social factors in the Pakistani society. For youth, social media is the most decisive factor for their brand selection, retaining, and switching.

In this regard, brand managers of smartphone developers have to be smart now. They should aim towards targeting social media as a primary means of branding. The only viable option to overcome brand switching is to drive social media forums as a medium to reach, lure and capture target customers. As discussed earlier, social media is the most influential factor of this era. Therefore, the desired brand loyalty cannot be attained without conquering social media platforms. Sales promotion is an essential component of the promotion mix, and it is meant to increase short 
term sales (Buil et al., 2013). It is therefore not surprising that most of the marketers utilize it to attract the competitor's loyal consumers. On a similar note, youngsters are always in search of promotional deals and therefore, they are an easy prey of cheap promotional deals. The products offered in sales promotions are mostly inexpensive and it is a neck breaking point for local and private brands.

In emerging economies like Pakistan, the trend of sales promotion is seeking abundant attention. On the other hand, the concept of brand loyalty is vanishing nowadays. Customers prefer shifting to the smartphone brands which have lucrative promotional offers. The ultimate upshot is the dominance of brand switching over brand loyalty. Thus, brand loyalty can be broken down with sales promotions, that too effortlessly in Pakistan.

On the contrary, brand switching can be controlled by developing sustainable brand loyalty programs. In order to make loyalty programs a success, marketers should go for other promotional programs like, digital advertising, mobile marketing and public relations. According to Keller et al. (2008) the unique and favorable brand associations can also assist to a great extent by breaking the spell of sales promotion among youngsters. Researchers defined variety seeking as a situation where consumers are satisfied with the existing product, but they search for other products with similar functionality. Most authors have termed it as 'need for uniqueness' (Junaedy \& Dharmmesta, 2002). Variety seeking is one of the considerable factors that create competition in the industry. Previously, it has been discussed that youngsters are very enthusiastic regarding their purchase and consumption choices in Pakistan.

Gronhoj (2007) explained that youngsters are mostly in search of unique and different products. Moreover, they want to look distinctive in their social circle. The same can be observed in the Pakistani culture as well as the youth are very savvy here. They are in touch with the global trends through the internet and television. In a society like Pakistan, it is not difficult to predict that youngsters would not remain loyal to a particular brand, especially when a plethora of national and international brands are present at their disposal. Their need for uniqueness compels them to shift between numerous brands. In this way, the concept of brand loyalty becomes blurred. 
However, smartphone developers can revitalize brand loyalty by offering different products with multiple features. Ahad and Anshari (2017) argue that the youth is the largest buyer of Smartphone industry worldwide. Therefore, the key target of Pakistani marketers should be youngsters. By building favorable and unique brand images, marketers can achieve higher levels of customer satisfaction as customer satisfaction is the ladder to brand loyalty. Once a large number of delighted customers are taken on board, it would be effortless for managers to dodge variety seeking even in cut throat competition. With the passage of time, delighted customers would turn into loyal consumers.

\section{Conclusions and Recommendations}

This research work has been executed in Pakistan to find out about the impact of various factors i.e. social influence, sales promotion and variety seeking on brand switching with a moderating effect of brand loyalty. The examination was conducted in context of the smartphone industry, following a quantitative research design. Most of the respondents that were approached in this study were young consumers (16-30 years old), because it is assumed that they might have had a high acceptance of smartphones (Sasmita \& Suki, 2015). For this study, 500 respondents were contacted, out of which, a total of 482 responses were administered for data analysis. The results depict that various factors are responsible for influencing youngsters to switch between various brands of smartphones. However, brand loyalty creates resistance in doing so. Furthermore, the findings appear to support the findings of the prior studies conducted. For example, following researchers have also (Belch et al., 2014; Jensen \& Hansen, 2006; Jung \& Yoon, 2012; Westberg \& Pope, 2014) elaborated that social influence, sales promotion and variety seeking have a direct positive relation with brand switching, and these factors enhance brand switching behavior.

These findings of this investigation can be used by the smartphone industry, and the related innovative and technological industry sectors. This is so because this study provides relevant information about the various factors that are likely to influence the intention of buyers to remain with or switch their smartphone brand. Interestingly, most of the institutions have a keen focus on boosting the skills and knowledge of their internal customers (employees) so that they can compete in international 
markets (Ali \& Muhammad, 2018). Therefore, this survey can assist organizations focusing on their employees for customer retention.

Furthermore, the managers of the smartphone organizations can utilize this information in the future to keep potential clients from switching. From the perspective of smartphone companies that are attempting to get the consideration of new customers, this research can assist them in creating methodologies, strategies and to implement tactics in order to overcome brand switching, retaining potential customers and expanding the market share.

\subsection{Limitations and Future Research Directions}

This research depends on the information concerning a single item industry (Smartphone) in just one country (Pakistan), which exhibits its restrictions. The findings and conclusions may not precisely apply to different products, industries and across the national boundaries of Pakistan. It is encouraged that future researchers should examine other moderators and mediators than just the brand loyalty, with a goal to explore the phenomenon from other perspectives as well.

Furthermore, it should likewise be considered here that the respondents' have answered with respect to their state of mind, perceptions, opinions and attitudes toward the brand switching experience. Therefore, it is difficult to assume that the outcomes are comprehensive and absolute, until and unless they are observed in a longitudinal research. It also infers that respondents should be approached for the long term, as well as to monitor their behavior. In this manner, their behavior regarding brand switching and brand loyalty might yield much more valuable results.

Last, the data was collected from university students only. It is suggested to investigate populations other than students so as to generalize the findings. To obtain more in depth information about consumers' brand retaining and switching behavior, this group could be studied in greater detail on the bases of other products, with more influencing factors. 


\section{References}

Ahad, A. D., \& Anshari, M. (2017). Smartphone habits among youth: Uses and gratification theory. International Journal of Cyber Behavior, Psychology and Learning, 7(1), 65-75.

Algesheimer, R., Dholakia, U. M., \& Herrmann, A. (2005). The social influence of brand community: Evidence from European car clubs. Journal of Marketing, 69(3), 19-34.

Al-Kwifi, S. O. (2016). The role of MRI in detecting attitude toward brand switching: an exploratory study using high technology products. Journal of Product \& Brand Management, 25(2), 208-218.

Al-Kwifi, O. S., \& Ahmed, Z. U. (2015). An intellectual journey into the historical evolution of marketing research in brand switching behavior-past, present and future. Journal of Management History, 21(2), 172-193.

Ali, A. (2017). Halal Products Purchase Intention in Pakistan: Evidences from Non-Muslim Community. Arabian Journal of Business and Management Review, 7(4), 1-6

Ali, A., \& Muhammad, A. K. (2018). Understanding the Role of Internship as an Activity Based Learning: A Case Study. Journal of Education and Educational Development, 5(2), 92-106.

Ali, A., \& Lodhi, R.N. (2017). How Facebook Addiction Affects the Personal Life of Addict Students and their Family: A Case Study of Pakistan. Paradigms: A Research Journal of Commerce, Economics, and Social Sciences, 11(2), 184-189

Ameen, K., \& Gorman, G. E. (2009). Information and digital literacy: a stumbling block to development? A Pakistan perspective. Library Management, 30(1/2), 99-112.

Batra, R., Ahuvia, A., \& Bagozzi, R. P. (2012). Brand love. Journal of Marketing, 76(2), 1-16. 
Baxendale, S., Macdonald, E. K., \& Wilson, H. N. (2015). The impact of different touchpoints on brand consideration. Journal of Retailing, 91(2), 235-253.

Belch, G. E., Belch, M. A., Kerr, G. F., \& Powell, I. (2014). Advertising: An integrated marketing communication perspective. North Ryde: McGraw-Hill Education.

Buil, I., Chernatony, L., \& Martínez, E. (2013). Examining the role of advertising and sales promotions in brand equity creation. Journal of Business Research, 66(1), 115-122.

Chadha, S. K., \& Kapoor, D. (2009). Effect of switching cost, service quality and customer satisfaction on customer loyalty of cellular service providers in Indian market. IUP Journal of Marketing Management, 8(1), 23.

Comrey, A. L., \& Lee, H. B. (1992). A First Course in Factor Analysis. Hillsdale, NJ: Lawrence Eribaum Associates.

Das, A., \& Khan, H. U. (2016). Security behaviors of smartphone users. Information \& Computer Security, 24(1), 116-134.

Dooley, R. S., \& Fryxell, G. E. (1999). Attaining decision quality and commitment from dissent: The moderating effects of loyalty and competence in strategic decision-making teams. Academy of Management Journal, 42(4), 389-402.

Esch, F. R., Langner, T., Schmitt, B. H., \& Geus, P. (2006). Are brands forever? How brand knowledge and relationships affect current and future purchases. Journal of Product \& Brand Management, 15(2), 98-105.

Gronhoj, A. (2007). The consumer competence of young adults: a study of newly formed households. Qualitative Market Research: An International Journal, 10(3), 243-264.

Gulati, P. (2009). Research Management: Fundamental and Applied Research, Delhi: Global India Publications 
Hair, J., Hair, J., Hollingsworth, C. L., Hollingsworth, C. L., Randolph, A. B., Randolph, A. B., ... \& Chong, A. Y. L. (2017). An updated and expanded assessment of PLS-SEM in information systems research. Industrial Management \& Data Systems, 117(3), 442-458.

Hair Jr, J. F., \& Hult, G. T. M. (2016). A primer on partial least squares structural equation modeling (PLS-SEM). Thousand Oaks, CA: Sage Publications.

Hair, J. F., Hult, G. T. M., Ringle, C. M., \& Sarstedt, M. (2013). A Primer on Partial Least Squares Structural Equation Modeling (PLS-SEM). Thousand Oaks, CA: Sage Publications.

Harris, F., Gordon, R., MacKintosh, A. M., \& Hastings, G. (2015). Consumer socialization and the role of branding in hazardous adolescent drinking. Psychology \& Marketing, 32(12), 1175-1190.

Hebblethwaite, D., Parsons, A. G., \& Spence, M. T. (2017). How brand loyal shoppers respond to three different brand discontinuation scenarios. European Journal of Marketing, 51(12), 1918-1937.

Heerde, H. J., Gupta, S., \& Wittink, D. R. (2003). Is 75\% of the sales promotion bump due to brand switching? No, only $33 \%$ is. Journal of Marketing Research, 40(4), 481-491.

Henseler, J., Dijkstra, T. K., Sarstedt, M., Ringle, C. M., Diamantopoulos, A., Straub, D. W., Ketchen, D. J., Hair, J. F., Hult, G. T. M., and Calantone, R. J. (2013). Common Beliefs and Reality about Partial Least Squares: Comments on Rönkkö \& Evermann. Organizational Research Methods, 17(2), 182-209.

Jensen, J., \& Hansen, T. (2006). An empirical examination of brand loyalty. Journal of Product \& Brand Management, 15(7), 442-449.

Jin, B. S., Yoon, S. H., \& Ji, Y. G. (2013). Development of a continuous usage model for the adoption and continuous usage of a smartphone. International Journal of Human-Computer Interaction, 29(9), 563-581.

Junaedy, S. \& Dharmmesta, B. S. (2002). The Influence of Consumer Dissatisfaction, Characteristics Product Category, and Variety 
Seeking on Brand Switching. Journal of Economics and Business Indonesia, 17(1), 91-104.

Jung, H. S., \& Yoon, H. H. (2012). Why do satisfied customers switch? Focus on the restaurant patron variety-seeking orientation and purchase decision involvement. International Journal of Hospitality Management, 31(3), 875-884.

Keller, K. L., Apéria, T., \& Georgson, M. (2008). Strategic brand management: A European perspective. Harlow, England: Prentice Hall Financial Times.

Khalek, A. A. (2014). Young consumers' attitude towards halal food outlets and JAKIM's halal certification in Malaysia. Procedia-Social and Behavioral Sciences, 121(1), 26-34.

Kotler, P. (2015). Framework for marketing management. New Delhi: Pearson Education India.

Kotler, P., \& Armstrong, G. (2010). Principles of marketing. New Jersey: Pearson (Education).

Kotler, P., \& Keller, K. L. (2016). Marketing Management. New Jersey: Pearson Pretice Hall.

Kim, D., Lee, S. Y., Bu, K., \& Lee, S. (2009). Do VIP programs always work well? The moderating role of loyalty. Psychology \& Marketing, 26(7), 590-609.

Kumar, S. S., \& Menon, R. P. (2017). Brand Loyalty of Customers in Smartphone Brands. Indian Journal of Marketing, 47(3), 8-15.

Lambert, R., \& Laurent, G. (2010). Why do older consumers buy older brands? The role of attachment and declining innovativeness. Journal of Marketing, 74(5), 104-121.

Lohmoller, J. B. (2013). Latent variable path modeling with partial least squares. Heidelberg: Springer. 
Msaed, C., Al-Kwifi, S. O., \& Ahmed, Z. U. (2017). Building a comprehensive model to investigate factors behind switching intention of high-technology products. Journal of Product $\mathcal{E}$ Brand Management, 26(2), 102-119.

McAlexander, J. H., Schouten, J. W., \& Koenig, H. F. (2002). Building brand community. Journal of Marketing, 66(1), 38-54.

Miller, T., Chandler, L., \& Mouttapa, M. (2015). A needs assessment, development, and formative evaluation of a health promotion smartphone application for college students. American Journal of Health Education, 46(4), 207-215.

Nagar, K. (2009). Evaluating the effect of consumer sales promotions on brand loyal and brand switching segments. Vision, 13(4), 35-48.

Narayan, V., Rao, V. R., \& Saunders, C. (2011). How peer influence affects attribute preferences: A Bayesian updating mechanism. Marketing Science, 30(2), 368-384.

Nguyen, T. D., Barrett, N. J., \& Miller, K. E. (2011). Brand loyalty in emerging markets. Marketing Intelligence \& Planning, 29(3), 222-232.

Norazah, M.S. (2013). Young consumer ecological behaviour: the effects of environmental knowledge, healthy food, and healthy way of life with the moderation of gender and age. Management of Environmental Quality: An International Journal, 24(6), 726-737.

Prasad, M. M., \& Kumar, D. P. (2016). Factors Influencing the Behavior of the Mobile Phone users to Switch their Service Providers in Andhra Pradesh. Global Journal of Management and Business Research, 16(5), 253-267.

Papatla, P. (2003). Brand inequalities in the loyalty-effects of purchases. Marketing Letters, 14(4), 361-368.

Ratner, R. K. and Kahn, E. B. (2002). The Impact of Private vs. Public Consumption on Variety-Seeking Behavior. Journal of Consumer Research, 29 (2), 246-57. 
Sahay, A., \& Sharma, N. (2010). Brand relationships and switching behaviour for highly used products in young consumers. Vikalpa, 35(1), 1-30.

Sasmita, J \& Suki, N. (2015). Young consumers' insights on brand equity: Effects of brand association, brand loyalty, brand awareness, and brand image. International Journal of Retail $\mathcal{E}$ Distribution Management, 43(3), 276-292.

Saunders, M., Lewis, P. \& Thornhill, A.(2012). Research methods for business students, 6 .

Sharma, V., Kapse, M., \& Sonwalkar, J. (2016). Predicting the Consumers' Brand Switching Behavior for Cellphones: Application of Markov Chain Models. IUP Journal of Marketing Management, 15(4), 31.

Sloot, L. M., \& Verhoef, P. C. (2008). The impact of brand delisting on store switching and brand switching intentions. Journal of Retailing, 84(3), 281-296.

Solomon, M. R. (2006). Consumer behaviour: Buying, selling and being. New Jersey: Pearson Prentice-Hall.

Suki, N. (2013). Students' demand for smartphones: Structural relationships of product features, brand name, product price and social influence. Campus-wide Information Systems, 30(4), 236-248.

Taute, H. A. \& Sierra, J. (2014). Brand tribalism: an anthropological perspective. Journal of Product \& Brand Management, 23(1), 2-15

Tavakol, M., \& Dennick, R. (2011). Making sense of Cronbach's alpha. International Journal of Medical Education, 2, 53.

Ullman, J. B., \& Bentler, P. M. (2003). Structural equation modeling. New Jersey: John Wiley \& Sons, Inc.

Villanti, A. C., Giovino, G. A., Barker, D. C., Mowery, P. D., Sevilimedu, V., \& Abrams, D. B. (2012). Menthol brand switching among adolescents and young adults in the National Youth Smoking Cessation Survey. American Journal of Public Health, 102(7), 1310-1312. 
Westberg, K., \& Pope, N. (2014). Building brand equity with cause-related marketing: A comparison with sponsorship and sales promotion. Journal of Marketing Communications, 20(6), 419-437.

Wong, K. K. K. (2013). Partial least squares structural equation modeling (PLS-SEM) techniques using SmartPLS. Marketing Bulletin, 24(1), 132.

Yeh, C. H., Wang, Y. S., \& Yieh, K. (2016). Predicting smartphone brand loyalty: Consumer value and consumer-brand identification perspectives. International Journal of Information Management, 36(3), 245-257. 